\title{
THE ASSESSMENT METHODOLOGY OF CHAMBER MINING SYSTEM ELEMENTS SUSTAINABILITY
}

\author{
Vladimir Asanov ${ }^{1 *}$, Anton Evseev ${ }^{1}$, Valeriy Toksarov ${ }^{1}$ and Nicholas Beltiukov ${ }^{1}$ \\ ${ }^{1}$ Mining Institute of the Ural Division of the Russian Academy of Sciences - Division of Federal state \\ budget institution of science of the Perm Federal research center of Ural Division of Russian \\ Academy of Sciences, Perm, Russia
}

\begin{abstract}
The forecasting method of roof treatment works stability in the silvinit seams mining of the Verkhnekamsk deposit of potassium salts, based on the strain properties determination of its constituent species in field conditions is examined. Key words: roof, interchamber intacts, salt rocks, stresses, strains, resistance
\end{abstract}

\section{Introduction}

One of the important conditions to ensure the safe conduct of underground mining is to control the stopes and development workings roof stability. Instrumental measurements allow adjusting the parameters of the industrial stocks project and take additional positive measures of working protection, if necessary. Compliance with this approach is especially important in the development of water-soluble ores, which safety testing relates to the need of the undermined strata continuity (of impermeable intact) preservation [1,2].

The object of the study is the Verkhnekamsk deposit of potassium and magnesium salts (VKDPM). Leaving the hard interchamber intacts, the silvinite seams ore mining are being developed by chamber mining system. The drifting of development workings and stopes is carried out by the combine method. Productive strata of the deposit, located at depths of $250-450 \mathrm{~m}$, is lamellar mass of silvinite and stone-salt rocks, often separated by clayanhydrite layers. Silvinite layers RfII and $\mathrm{AB}$ an average power of 5.0 and $3.5 \mathrm{~m}$ are respectively separated from each by other technological interlayers (RfII -AB) with a capacity of $2.5-8.0 \mathrm{~m}$. The roof of the working layers (especially RfII) overlain by having low resistance clay-salt rocks (cake) layers. With the strength characteristic of red silvinite 23.0 MPa [2] the strength of the silvinite seam RfII can be $1.5-2.0$ times below the average values for the field. Strength and deformation clayey material properties are directly in 1015 times lower than the properties of the rock salt layers and silvinite [3].

So at the opening of Polovodovsky block VKDPM reserves it is identified, that the clay material content in productive strata is $17-25 \%$, and clay layers capacity reaches up to $0.5-$ $0.7 \mathrm{~m}$. With the low strength and deformation properties are correspond to the first layer of interlayer RfI - RfII, where there is the highest content of clay material (table. 1).

\footnotetext{
${ }^{*}$ Corresponding author: ava@mi-perm.ru
} 
Table 1. The salt rocks properties study results of productive strata 1 YUVP of "EuroChem - UKK"

\begin{tabular}{|c|c|c|c|c|c|c|}
\hline $\begin{array}{c}\text { Layer, } \\
\text { stratum }\end{array}$ & Rock & Clay content & $\begin{array}{c}\text { Compressive } \\
\text { resistance }\end{array}$ & $\begin{array}{c}\text { Tensile } \\
\text { strength }\end{array}$ & $\begin{array}{c}\text { Modulus of } \\
\text { deformation }\end{array}$ & $\begin{array}{c}\text { Elastic } \\
\text { modulus }\end{array}$ \\
\cline { 2 - 7 } & $\%$ & $\mathrm{MPa}$ & $\mathrm{MPa}$ & $\mathrm{GPa}$ & $\mathrm{GPa}$ \\
\hline $\begin{array}{c}\text { RfI-RfII } \\
\text { (cakes) }\end{array}$ & rock salt & 39.6 & 1.23 & 0.21 & 0.0567 & 0.11 \\
\hline Rf21r1 & red silvinit & 19.8 & 13.73 & 1.44 & 0.49 & 5.29 \\
\hline Rf21r2 & rock salt & 22.5 & 15.48 & 1.39 & 0.55 & 6.50 \\
\hline Rf21r3 & red silvinit & 7.7 & 15.00 & 1.72 & 0.56 & 6.04 \\
\hline Rf21r4 & rock salt & 15.7 & 19.00 & 1.83 & 0.83 & 7.08 \\
\hline Rf21r5 & red silvinit & 7.6 & 19.02 & 1.34 & 0.64 & 8.03 \\
\hline Rf21r6 & rock salt & 15.7 & 23.00 & 1.78 & 0.76 & 7.31 \\
\hline Rf21r7 & red silvinit & 4.0 & 22.12 & 1.52 & 0.72 & 9.06 \\
\hline Rf2-Rf3 & rock salt & 11.1 & 23.62 & 1.76 & 0.95 & \\
\hline
\end{tabular}

\section{The roof rocks stability analysis}

When working out the south-eastern sections reserves of the deposit, characterized by a high content of clayey material in the mined strata roof, the problem to ensure the conservation of the roof stopes had intensified. So when working out the reserves on 9-11 eastern panel of the mine BKPRU-2, camera width $5.5 \mathrm{~m}$, where the clay content of material on average is $12-15 \%$, there was intensive balmstoning in the roof, leading to violation of technological process and creates hazardous conditions for miners. A number of cameras failed to finish until the end for sinking of heading machine because of the danger of their "gripping" and a high probability of roof collapse.

Despite the presence of roof bolting, examination of exhaust chambers showed that, a small roof appear within the first weeks after the sinking, and after 1.5-2.0 months marked the collapse of the roof rocks of a large area and partial destruction of the interlayer RfII-AB.

With the aim of establishing the main regularities of deformation processes development in water treatment chambers depending on the geological conditions of mining operations conducted complex long-term field studies of the deformation nature of the system development structural elements, which included measurement of deformations for interchamber intacts, roof extraction chambers and interlayers.

Contour and deep bench mark system was the design of the metering station.

The central part of the mine at each metering station had a 4 deep bench mark with a length of $0.5,1.0,1.5$ and $2.0 \mathrm{~m}$, and two sets of contour bench marks for monitoring the chambers roof and walls convergence on both layers (Fig.1a). The study results analysis showed that there is intense stratification of seam roof rocks for RfII with the subsequent clay layers collapse, within the first 1.0 to 2.5 months after the advancement. All layers of technological interlayers $\mathrm{RfII}-\mathrm{AB}$ are involved in this deformation. 
During the 54 days of observation the seam roof deformation RfII in chamber No. 137 (9 VP) was about $200 \mathrm{~mm}$, there was observed uniform character of deformation of the roof across its power (Fig. 1, b).

At the approach of mining operations to the metering station is to increase the speed of rocks soil deformation on the layer $\mathrm{AB}$ to $5.5-6.0$ times. The rate of deformation for soil rocks extraction chamber is stabilized at the same level In the future. In the north-eastern part of the mine field mine BPKRU-2, where the clay content is much less, the bulk of the deformation accounts for the marginal layer of the seam roof RfII, while strains an order of magnitude less [4].
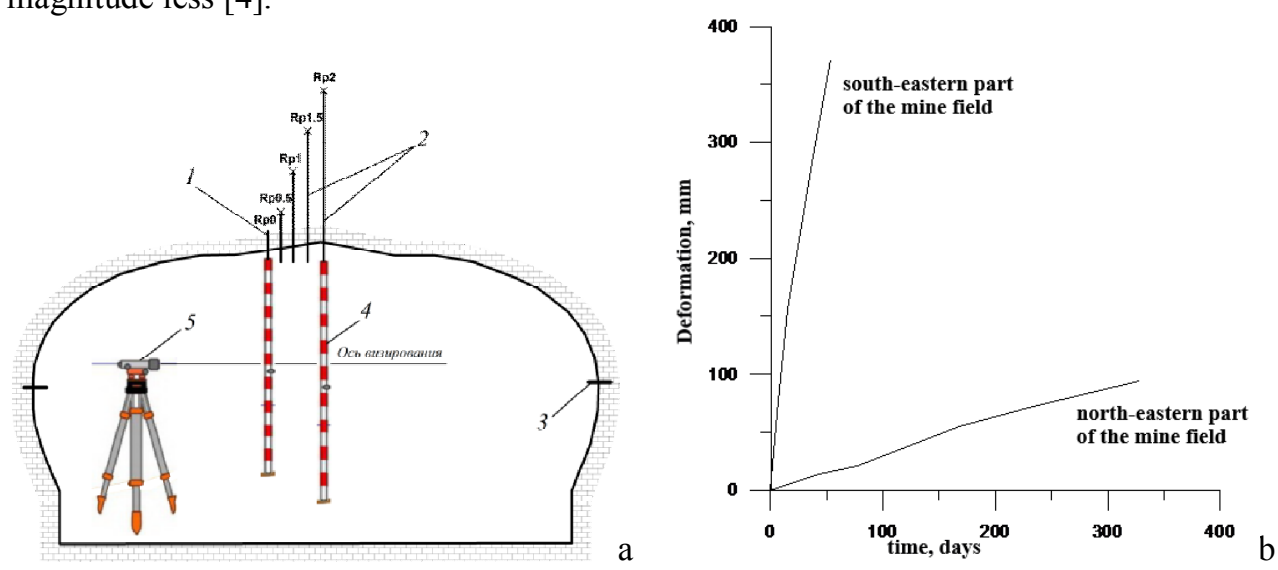

Fig.1. The measurement scheme (a) and the subsidence roof layer $\mathrm{Kr}$ (b) graph

The implermented studies complex have shown that it is necessary to know the physicomechanical properties of rocks for the outcrops stability justification, taking into account structural and their structure textural features, which can be evaluated to the strength and deformation properties study of adjacent strata in mass.

The loading circuit layer methods of the rock hydraulic load devices with various designs is widely used for their definition: flat metal spinning units, downhole hydraulic jack.

\section{Experimental test procedures}

The field studies complex to determine the deformation modulus of rocks in-circuit mass using Goodman's hydraulic jack[5], which represents a logging sonde designed to measure deformation of the borehole walls under the action of the applied load (Fig. 2) are made for a substantiation the criteria of roof rocks sustainability for extraction chambers.

The borehole walls loading is carried out by two movable metal plates at each end which are mounted the displacement sensors. During the strain indicators field measurements, the following procedure is carried out. Hydraulic jack is placed in the borehole at the required depth. Then using the hand-pump working fluid is supplied into the cylinder of the measuring device (to the level of pressure $15-20 \mathrm{MPa}$ ). During the experiment check of strains every 2 to $5 \mathrm{MPa}$. After the loading is done stepwise unloading. Each measuring point was performed $2-3$ the measurement cycle in the "load-unload". The measurements are performed using $0.3 \mathrm{~m}$ distance from the contour of the outcrop. The maximum well depth is $3,5-5,0 \mathrm{~m}$. 


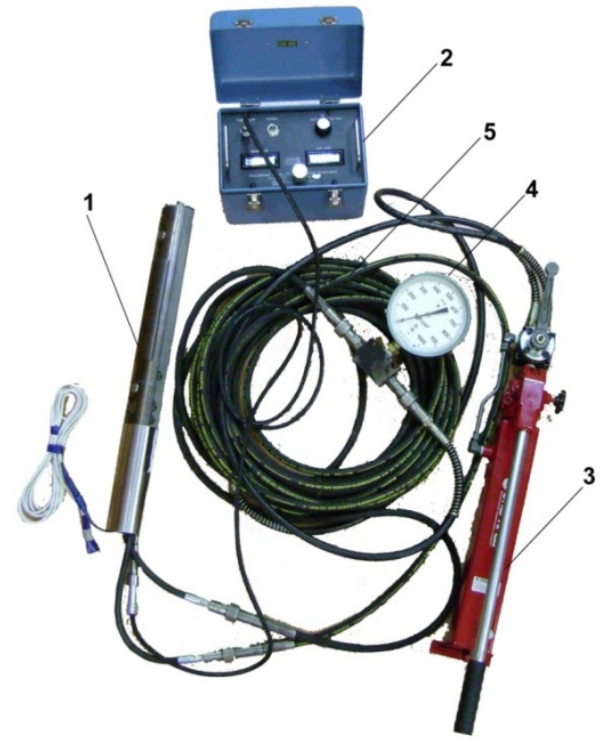

Fig. 2. Equipment set for the modulus of deformation salt rocks determining in field conditions: 1 hydraulic jack; 2 - a portable device for measuring deformation; 3 - hand pump; 4 - manometer; 5 pressure hoses

As a result of the experimental studies graphs "pressure (Q), radial strain ( $\varepsilon d)$ " which are determined by the deformation parameters of the mass. There are three characteristic stages (Fig. 3) In the borehole walls deformation diagrams.

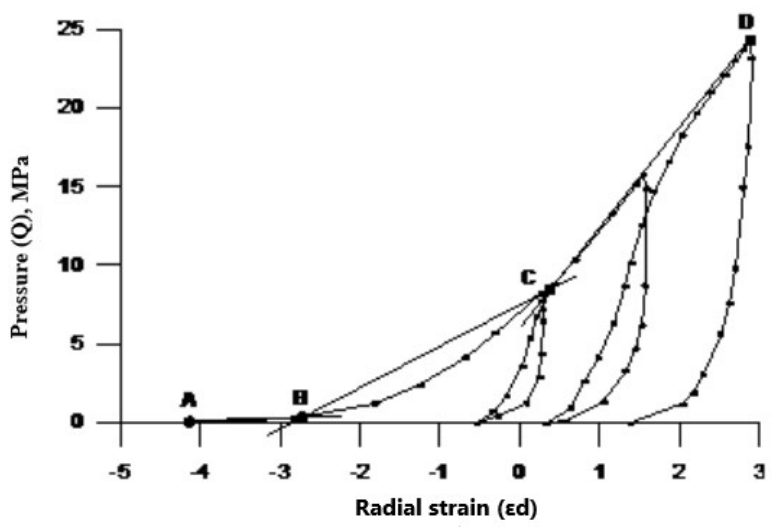

Fig. 3. The borehole walls deformation graph

In the first stage, the movement of the pressure plates to contact with the borehole wall (segment $\mathrm{AB}$ ) is being. The second stage is timed (segment $\mathrm{BC}$ ) to bulging-in borehole walls jack irregularities. The third stage corresponds to the complete contact of the pressure plates with the walls of the bore and the deformation of the circuit layer of the rock. The modulus of deformation is calculated by the tangent at the site of a full contact of the pressure plates with the walls of the well.

Studies of the deformation properties of rock prisms pre-loading them according to the stress condition that exists in the mass (Fig. 2) was also undertaken for method development. The prism loading of is carried out by hydraulic jack with a maximum force of 100 t. Prior to testing, the sample surface is levelled using a layer of salt chips with a 
thickness of $1-2 \mathrm{~cm}$. The chips are compressed under load, compacted and ensures uniform transmission of pressure from the plate to the block. Then was the drilling of the measuring wells, in which hydraulic jack was installed, carried out and loading block was made from inside. The studies of the mechanical properties on samples with a diameter of $50 \mathrm{~mm}$. were performed in parallel laboratory.
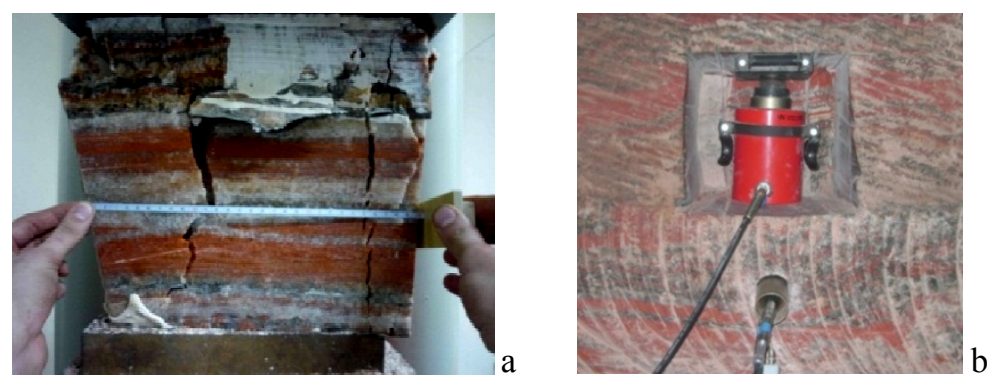

Fig.4. Determining the salt rocks modulus of deformation in laboratory (a) and field conditions (b)

As a result of researches it is established that the modulus of deformation of salt rock, defined in field conditions ranges from 0.5 to $2.7 \mathrm{GPa}$ and depends on the stress level. With the increase of stresses in the mass marked increase in the modulus of deformation. The laboratory studies results tend to give higher (10-20\%) values of the designated indicators (table. 2).

Table 2. The modulus of deformation of rocks formations KrII-KrI and KrII (mine workings BKPRU-2)

\begin{tabular}{|l|l|c|c|c|}
\hline \multirow{2}{*}{$\begin{array}{l}\text { Designation rock, } \\
\text { seam }\end{array}$} & \multicolumn{1}{|c|}{ Determining method } & \multicolumn{3}{|c|}{ The modulus of deformation the rock, } \\
\cline { 3 - 5 } & & & \multicolumn{3}{|c|}{ GPa } \\
\cline { 3 - 5 } & & $11 \mathrm{VP}$ & $9 \mathrm{VP}$ & $20 \mathrm{ZP}$ \\
\hline $\begin{array}{l}\text { Rock salt, RfII- } \\
\text { RfI }\end{array}$ & Laboratory tests & 0,933 & 1,360 & 1,560 \\
\cline { 2 - 5 } & Mining measurement & 1,350 & 1,061 & 1,260 \\
\hline $\begin{array}{l}\text { Red silvinite, } \\
\text { RfII }\end{array}$ & Laboratory tests & 1,421 & 1,363 & 2,360 \\
\cline { 2 - 5 } & Mining measurement & &
\end{tabular}

The modulus of elasticity is on average 4 to 5 times higher than the modulus of deformation. These values correlate well with values of deformation properties of salt rocks determined in the laboratory on small sized samples. This suggests that the scale effect influence in the salt rocks is insignificant [4].

\section{Discussion of results}

The large amount of field research carried out in the mines of "Uralkalii" OJSC has shown that the deformation modulus varies in the interlayer rocks $\mathrm{RfII}-\mathrm{AB}$ within a fairly wide range from 0.7 to $3.0 \mathrm{GPa}$ In the depth interval of $0.5-1.5 \mathrm{~m}$ from the contour of the outcrop noted its growth from 1.2 to 2.0 GPA. There is an increasing of the modulus of deformation up to $2.5 \mathrm{GPa}$ in the middle of interlayers (in the depth interval of $2.7-3.2 \mathrm{~m}$ ), and then, it is reducing to $0.9 \mathrm{GPa}$, when approaching the overlying soil layer of the $\mathrm{AB}$.

Simultaneously with the evaluation of deformation properties in the marginal layer, the voltages measurement based on the use of acoustic emission memory effects, is well manifested in quasiplastic salt rocks [4] was carried out. Studies have found that in the middle of interlayers RfII - AB the magnitude of the horizontal stress varies from 5.0 to 7.5 $\mathrm{MPa}$. Near the roof of the reservoir RfII and in the soil layer of the AB voltage is reduced 
to $1.5 \mathrm{MPa}$, which indicates the destruction of the marginal layer of rocks and confirms the results of studies on the nature of deformation and destruction of rocks interlayers at high clay content. Telemetric examination of the walls of the measuring wells also confirmed the presence of zones of high fracture and delamination in the top layer RfII and in the soil layer $\mathrm{AB}$.

The joint studies analysis of the deformation nature and roof treatment fracture of stopes and the determination results for the modulus of deformation in field conditions has led to the conclusion that the critical value of the modulus of deformation near the outcrop in which there is intense stratification and the roof rocks collapse of the treatment chamber with the existing parameters of mining is $1.1 \mathrm{GPa}$ (Fig. 5).

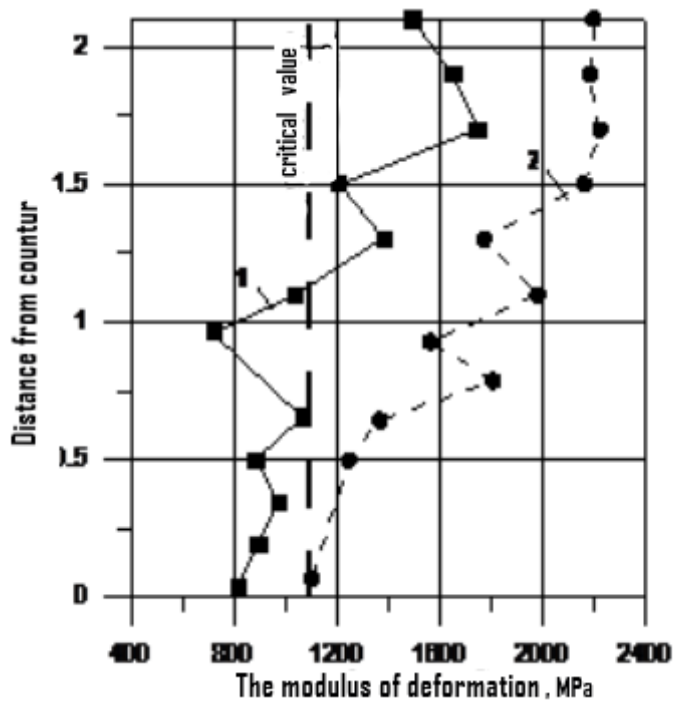

Fig. 5. The dependence of the rocks interlayers modulus deformation with distance from the contour of the exposure (the mine BKPRU-2): 1 - extraction chambers roof is unstable (9 VP); 2 - extraction chambers roof is steady (20 ZP)

So when the width of the extraction chambers more than $5.5 \mathrm{~m}$ and in the modulus of deformation less $1.1 \mathrm{GPa}$ the separation process of roof extraction chambers with the consequent loss of its stability is dramatically intenses. When the module of deformation is from 1.5 to 2.5 GPA salt rocks of interlayers are rocks of medium resistance, which contain no more than $5-6 \%$ of clay material, which allows to develop reserves of chambers without the technological complications, the term steady state of the roof extraction chambers is approximately one year. When the module of deformation is more than 2.5 $\mathrm{GPa}$ of the host rock are characterized by high homogeneity (absence of clay "cakes" are working in the roof layers), have a high roof resistance, providing exposure on large areas (with a width of chambers up to $16 \mathrm{~m}$ ) for up to several years

\section{Conclusions}

Thus, the modulus of deformation measured in full scale, is a comprehensive indicator of the salt mass structural heterogeneity, allowing it to be used for the assessment of the species sustainability. On the research basis the sustainability assessing methods of the rocks roof extraction chambers during the mining of silvinit seams in the mines VKDPM are developed. The stopes control stability task(safety of mining operations) during the mining of silvinite seams can be divided into two stages. The first step is to assess the degree of danger (risk) discontinuity waterproof strata to identify potentially dangerous 
areas for development opportunities emergency. Geological survey documentation obtained in the course of operational intelligence, the acts of inspection stopes and development workings, the data on land subsidence, the results of geophysical and seismological research is initial information to evaluate the undermined massif state of potentially dangerous areas. In the second phase, selected dangerous sections of the mine field runs comprehensive monitoring of load-carrying elements of the development system and the water column. In these areas, studies of physico-mechanical properties of the main lithological types of salts rock shall be performed, the evaluation of the stress-strain state and destruction in time for Interchamber intacts and interlayers are assessed. According to the results of experimental studies the intact deformation models, displacement of rocks and earth's surface when working out of the working layers clarifies. The implementation of multivariant calculations of stress-strain state of the salt mass in the process of mining for specific mining-geological conditions allows to evaluate the stability degree of chamber systems load-carrying elements and the danger of discontinuity VZT [6, 7, 8]. This technique can be adapted for use in similar conditions.

\section{References}

1. Federal norms and rules in the field of industrial safety "Safety regulations for the mining and processing of solid minerals": approved by the order of Rostechnadzor dated 11.12.2013, no 599 .

2. Guidelines for the protection of mines from flooding and protection of undermined objects in the conditions of the Verkhnekamsk deposit of potassium salts. Perm (2014).

3. 3. A. A. Bariakh, V.A. Asanov, I.L. Pankov. Physico-mechanical properties of salt rocks of the Verkhnekamsk deposit of potassium / tutorial. (2008).

4. 4. V.A. Asanov, V.N. Toksarov, A.V. Evseev, N.L. Beltiukov Behevioral of working roof on the southern flank of the Verkhnekamsk deposit of potassium salts. Phys. Tech. Probl. Mineral resources. No.1 (2012).

5. "Suggested Method for Estimating the In-Situ Modulus of Deformation of Rock Using the NX-Borehole Jack", by Heuze, F.E., ASTM Geotechnical Testing Journal, GTJODJ. 7 (4). (1984).

5. 6. V.A. Asanov, A. A. Bariakh, V.N. Toksarov, A.V. Evseev. The geomechanical assessment method for interchamber intacts long-term stability// Scientific and technical support of mining production (collection of scientific works. D.A. Kunaev Institute of Mining Engineering), 87. (2015).

7. Analysis of time-to time variation of load on interchamber pillars in mines of the Upper Kama potash salt deposit Baryakh A.A., Lobanov S.Y., Lomakin I.S. / Journal of Mining Science. 51 (4). Pages 696-706. (2015).

8. A.A. Bariakh, I.A. Sanfirov, A.K. Fedoseev, A.I. Babkin, A.A. Tsayukov, Seismic and geomechanical prediction of the waterproof strata state at the potash mines // Physicaltechnical problems of mining. 6. pp. 10-22. (2017). 